\title{
Reservoir characteristics and control factors of Tongbomiao formation in Hongqi sag
}

\author{
Wu Haibo ${ }^{1}$, Zhou Yue $^{1 *}$, and Chen $\mathrm{Hao}^{1}$ \\ ${ }^{1}$ Exploration and Development Research Institute of Daqing Oil Field Co. Ltd, Daqing City, Heilongjiang Province, 163712, China
}

\begin{abstract}
Hongqi sag is located in the north of Beiehur depression in Hailar Basin, which is a secondary structural unit in the peripheral depression of Hailar Basin, with great exploration potential. Based on SEM, conventional thin sheet, cast thin sheet, mercury pressure and physical property data, this paper discusses the reservoir characteristics, types and control factors of high quality reservoir in Tongbomiao formation, Hongqi sag, so as to provide a strong geological basis for the exploration of oil and gas in this area. The reservoir space of Hongqi sag is mainly composed of four types: primary intergranular pore, micro fracture, feldspar dissolution pore and debris dissolution pore. It is of the type of ultra low porosity and low permeability. Although Tongbomiao formation in Hongqi sag is of very low porosity and low permeability type, high quality reservoir is still developed, and its reason is mainly controlled by sedimentary environment, diagenesis and structural fracture.
\end{abstract}

\section{Introduction}

The characteristics and formation mechanism of clastic rocks in continental fault depression basin have been a hot issue, and many scholars have done more work in these aspects. Hailar Basin is a complex multi-stage superimposed fault basin. In recent years, there are many discussions on the physical control factors of the reservoir in Hailar Basin ${ }^{[1][2][3]}$. Hongqi sag has experienced multistage structural transformation and superimposed fault depression, and the influencing factors of reservoir physical properties are complex and diverse, and the distribution law is not clear. With the development of exploration, the physical properties of clastic rock reservoir are the important factors to control oil and gas. Therefore, it is of great significance to find high quality reservoirs. Many scholars have made important progress in the formation environment, diagenesis, pore type and physical characteristics of reservoirs. However, there are still some controversies about the main factors of high quality reservoirs in cupbimiao formation in Hongqi sag. Therefore, based on SEM, conventional thin sheet, cast thin sheet, mercury pressure and physical data, this study advances the reservoir characteristics and main control factors of cupbimiao formation in Hongqi sag The detailed analysis provides a strong geological basis for the exploration of oil and gas in the area.

\section{Regional overview}

Hongqi sag is located in the north of beierhu depression in Hailaer basin. It is distributed in northeast direction, adjacent to bayanshan uplift in the East and cuogang uplift in the West. It can be divided into 9 structural units: concave hill, cuogang uplift, Hongqi ranch sag, shutenor sag, central uplift fault zone, Hongxi inversion structural zone, shaoerbaoge slope zone, bayanshan uplift and wuxingdui uplift. It is characterized by "East-West zonation and North-South zonation", with an area of about $1000 \mathrm{~km}^{2}$ and a maximum burial depth of $3400 \mathrm{~m}$.

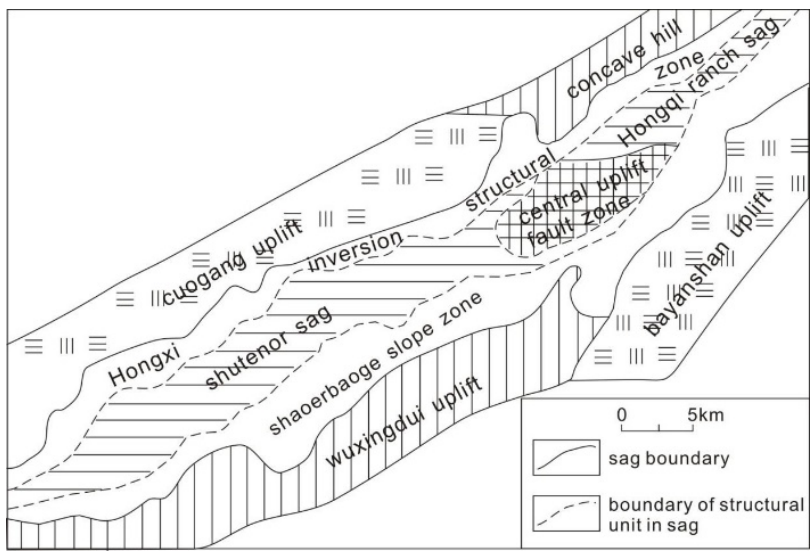

Figure 1. Structural unit division and stratigraphic histogram of Hongqi sag in Hailaer Basin.

The strata can be divided into Tamulangou formation, Tongbomiao formation, Nantun Formation, Damoguaihe Formation and Yimin formation from bottom to top. The Tamulangou formation is mainly composed of pyroclastic rocks and dark mudstone; the Tongbomiao and Nantun formations are mainly composed of fine sandstone, glutenite and dark mudstone; the Damoguaihe Formation is mainly composed of grey mudstone; the Yimin formation is composed of grey black shale interbedded with siltstone and fine sandstone; the Qingyuangang

\footnotetext{
*Corresponding author: 47310372@qq.com
} 
formation is mainly composed of brownish yellow glutenite. Among them, Tongbomiao formation shows good oil and gas, which is the research focus of the sag (Fig. 1).

\section{Petrological characteristics of reservoir}

Through the analysis of thin section identification data, the reservoir rock types of Tongbomiao formation in Hongqi sag are various and the heterogeneity is strong. The reservoir rock types are mainly feldspar lithic sandstone and lithic sandstone (Fig. 2a). The content of quartz in clastic components is relatively low, and the content of feldspar and cuttings is relatively high, with the average volume fraction of feldspar accounting for $23.8 \%$ of the total clasts; the average volume fraction of quartz is $16.2 \%$; the content of cuttings is relatively high, with the average volume fraction of $49.8 \%$. The composition of cuttings is complex, mainly including magmatic rock and sedimentary rock cuttings. Among them, the content of magmatic rock cuttings is relatively high, accounting for $82 \%$ of the total volume content of relative cuttings. The magmatic debris are mainly trachyandesite, tuff, trachyte, andesite and basalt. The content of andesite and basalt is relatively high (Fig. 2b). The interstitial materials are chlorite, kaolinite, carbonate and siliceous. The average volume fraction of the interstitial materials is $10.5 \%$. The cement is mainly carbonate cementation, a small amount of siliceous cementation, kaolin and authigenic chlorite formed after feldspar dissolution are relatively more; the miscellaneous base is mainly argillaceous and pozzolanic, which are mixed and accumulated between particles, so it is difficult to define their relative content.
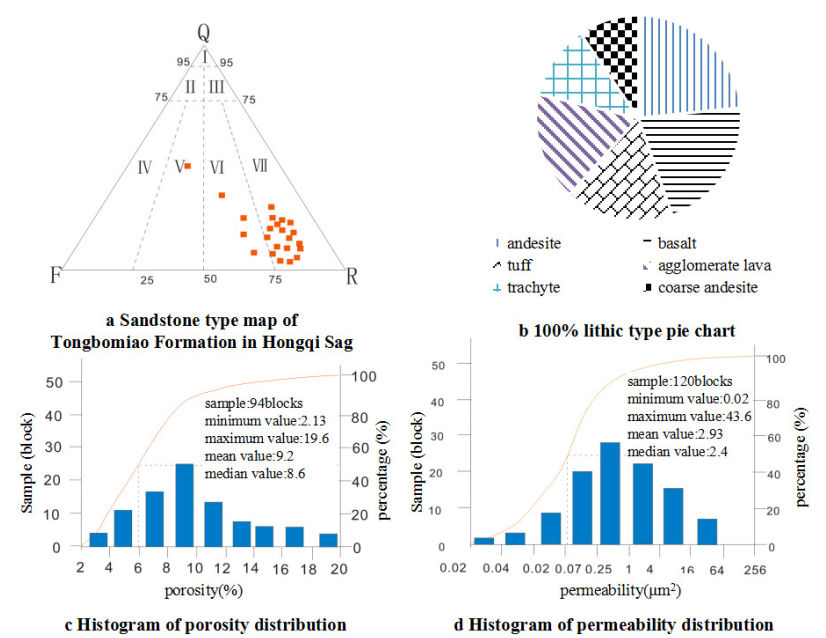

Figure 2. Sandstone types and porosity permeability istogram of Tongbomiao formation in Hongqi sag.

The reservoir rocks are poorly sorted, with sub angular and sub circular roundness, various cementation modes, mainly pore cementation, contact cementation and basement cementation, and low compositional maturity and structural maturity; the support type of rocks is particle support; the point line contact is the main contact between particles. Through thin section and scanning electron microscope, it is found that there are various pore types in the reservoir, including primary intergranular pore, feldspar solution pore and cuttings solution pore, and a small amount of clay mineral intergranular pore and fracture pore (Fig. 3). Among them, primary intergranular pores account for $18 \%$ of the total pore body, feldspar dissolved pores account for $36 \%$ of the total pore body, cuttings dissolved pores account for $37 \%$ of the total pore body, microfractures account for $7 \%$ of the total pore body, and clay mineral intergranular pores account for $2 \%$ of the total pore body. According to the national oil and gas industry standard, the porosity of Tongbomiao formation reservoir in Hongqi sag mainly ranges from 6 to $19.6 \%$, with an average of $9.2 \%$ (Fig. 2c), and the permeability mainly ranges from 0.02 to $43.6 \times 10^{-3} \mu \mathrm{m}^{2}$, with an average of $2.93 \times 10^{-3} \mu \mathrm{m}^{2}$ (Fig. $2 \mathrm{~d}$ ), which is an ultra-low porosity and low permeability reservoir.
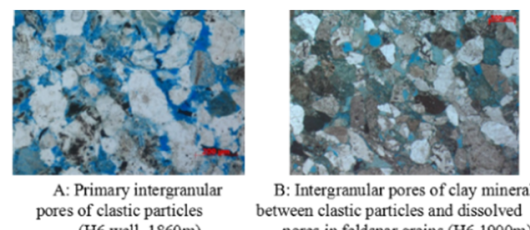
B: Intergranular pores of clay mineral
between clastic particles and dissolved (H6 well, 1860m)
(1)
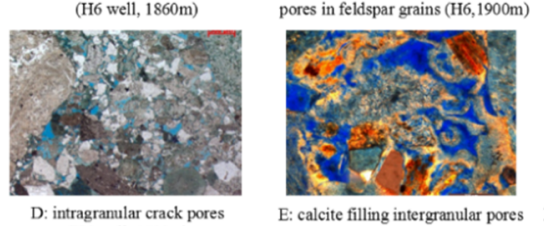

(H6 well, $1500 \mathrm{~m})$
(intragranular crack por

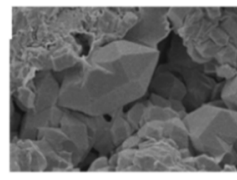

G: microcrystalline quartz cladding (H5, 2151m)

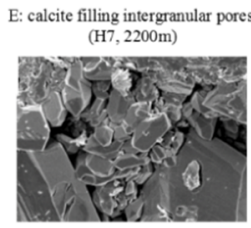

H: Quartz is secondary to increase (
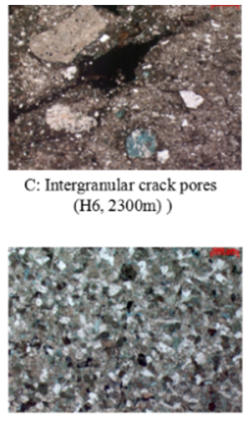

filling intergranular pores

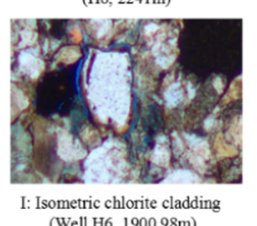

(Well H6, 1900.98m)
Figure 3. Pore types of Tongbomiao formation in Hongqi sag.

\section{Analysis on controlling factors of high quality reservoir}

Although Tongbomiao formation in Hongqi sag is an ultra-low porosity and low permeability reservoir, high quality reservoir is still developed, which is mainly controlled by sedimentary environment, diagenesis and structural fractures.

\subsection{Depositional environment}

Sedimentation controls the physical properties of the original reservoir. Under the action of different sedimentary environments, the particle size, rounding, sorting and impurity content of the sediments are obviously different under different sedimentary dynamic conditions. Therefore, the sedimentary environment will have a direct impact on the physical properties of rocks. The results show that porosity is negatively correlated 
with shale content. Low argillaceous content, strong hydrodynamic conditions, good sand sorting and grinding, strong anti compaction ability, which is conducive to the preservation of primary pores, more conducive to the generation of secondary pores in the later stage, and easy to form high-quality reservoirs. The reservoir of Tongbomiao formation in Hongqi sag mainly develops fan delta system. The physical properties of underwater distributary channel microfacies in fan delta front and above water distributary channel microfacies in fan delta plain are better than those of sheet sand and sublacustrine fan in fan delta front.

\subsection{Diagenesis}

Diagenesis includes the influence of compaction, cementation, chlorite film, pyroclastic materials on dissolution, which controls the formation, evolution and distribution of reservoirs ${ }^{[4][5]}$. The diagenesis of the reservoir in the study area mainly includes compaction, cementation and dissolution. According to the vertical variation of clay minerals, authigenic minerals and pore types, the Tongbomiao formation in Hongqi sag is in the middle diagenetic stage A-B (Fig. 4).

\begin{tabular}{|c|c|c|c|c|c|c|}
\hline \multirow{13}{*}{ 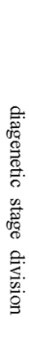 } & diagenetic stage & $\begin{array}{l}\text { early diagenetic } \\
\text { stage A }\end{array}$ & $\begin{array}{l}\text { early diagenetic } \\
\text { stage B }\end{array}$ & \begin{tabular}{l|}
$\begin{array}{l}\text { middle diagenetic } \\
\text { stage A }\end{array}$ \\
\end{tabular} & \begin{tabular}{l|}
$\begin{array}{l}\text { middle diagenetic } \\
\text { stage B }\end{array}$ \\
\end{tabular} & $\begin{array}{l}\text { late diagenetic } \\
\text { stage }\end{array}$ \\
\hline & paleogeotherm $/{ }^{\circ} \mathrm{C}$ & $<65$ & $65 \sim 85$ & $85 \sim 140$ & $140 \sim 175$ & $175 \sim 200$ \\
\hline & $\mathrm{R}_{\mathrm{d}} \% \%$ & $<0.35$ & $0.35 \sim 0.50$ & $0.5 \sim 1.3$ & $1.3 \sim 2.0$ & $2.0 \sim 4.0$ \\
\hline & $T_{M A X}{ }^{\circ} \mathrm{C}$ & $<430$ & $430 \sim 435$ & $435 \sim 460$ & $460 \sim 490$ & $>490$ \\
\hline & hydrocarbon evolution & \multicolumn{2}{|r|}{ biogas } & mainly crude oil & condensate oil & dry gas \\
\hline & compaction operation & \multicolumn{5}{|c|}{ 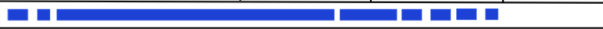 } \\
\hline & chlorite & \multicolumn{5}{|c|}{ 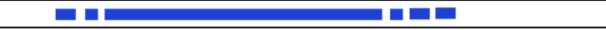 } \\
\hline & kaolinite & \multicolumn{5}{|c|}{ 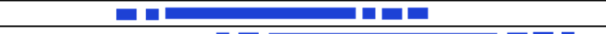 } \\
\hline & illite & \multirow{2}{*}{\multicolumn{5}{|c|}{ 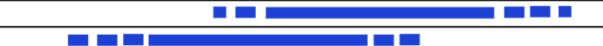 }} \\
\hline & calcite & & & & & \\
\hline & iron calcite & \multicolumn{5}{|c|}{ 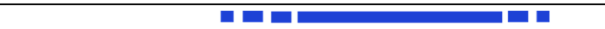 } \\
\hline & siliceous & \multirow{2}{*}{\multicolumn{5}{|c|}{ 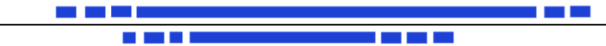 }} \\
\hline & dissolution & & & & & \\
\hline
\end{tabular}

Figure 4. Pore types of Tongbomiao formation in Hongqi sag.

Compaction is the main diagenesis to reduce the reservoir physical properties, and it is a destructive diagenesis to the reservoir physical properties. The buried depth of Tongbomiao formation in Hongqi sag is between 1800 and $3400 \mathrm{~m}$, with an average of $2600 \mathrm{~m}$. The maturity of rock composition and structure are low, and the rock compression capacity is weak. The rock particles are mainly point line contact, some of them are concave convex contact, and the intergranular pores are damaged. At the surface contact of rock particles, the carbonate produced by early cementation can effectively reduce the damage of compaction to the original reservoir, support and reduce the damage of compaction to the original pores, so that the original reservoir can be effectively preserved.

The reservoir of Tongbomiao formation in Hongqi sag is mainly composed of carbonate, kaolin and chlorite. According to the experimental analysis, there are two forms of carbonate cementation: the filling of intragranular pores; under the microscope, the pyroclastic particles are replaced by calcite, and the pyroclastic particles are dissolved to form intragranular dissolution pores; the calcite carbonate fills intragranular dissolution pores in the form of clumps and grains; Intergranular pore filling, carbonate recrystallization is massive, filling the primary intergranular pore, which has a destructive effect on the primary intergranular pore (Fig. 3E, F). Kaolin is cemented in intergranular solution pores, and alkaline feldspar dissolves to form kaolin. Kaolin recrystallizes and distributes in the pores in the form of film, strip and block. In intergranular pores, kaolin and volcanic ash are mixed together, and the boundary is not clear, so it is difficult to distinguish, which has a destructive effect on the primary intergranular pores. Chlorite cement is mainly attached to the surface of particles in the form of tufts and leaves. When the chlorite content is less than $16 \%$, the porosity increases with the increase of chlorite content; When the content is more than $16 \%$, the porosity increases and decreases. As there is no chlorite film at the contact of particles, the chlorite film is formed after strong compaction, which has a protective effect on the primary pores of the reservoir. Microscopic observation shows that there are a large number of intergranular pores in authigenic chlorite with good connectivity, which can be used as an effective reservoir space (Fig. 3G).

The reservoir of Tongbomiao formation in Hongqi sag is affected by compaction and diagenesis, and the loss of primary pores is large. The dissolution pores can effectively improve the physical properties of the reservoir, which is constructive diagenesis. The pyroclastic materials are easy to be dissolved, and the secondary pores are mainly formed by the dissolution of secondary glass and crystal fragments. Tuffaceous is easy to form dissolution pores and effectively improve reservoir physical properties (Fig. 3C, D). In the process of compaction and diagenesis, with the increase of burial depth, pyroclastic materials have relatively strong anti compaction ability, so that the primary pores can be effectively preserved. With the gradual increase of organic matter maturity, a large number of organic acids and acid gases are released, and the acidity of formation fluid is gradually enhanced. Pyroclastic materials are easy to form secondary pores under the condition of acidic water with good fluidity (Fig. 3E).

\subsection{Structural fracture}

Microfractures produced by tectonism are favorable for improving reservoir physical properties. Hongqi sag has experienced multi-stage tectonic movement. A large number of fault systems developed in the sag. The fault system is not only the channel and reservoir space for oil and gas migration, but also the favorable place and infiltration channel for dissolution. The dissolved matter can be removed with the fluid, which is conducive to the development of secondary pores. The microfracture reservoir in Hongqi sag is mainly caused by tectonism. The overall extension direction of microfracture in the study area is the same as that of the fault system. A few of microfractures are controlled by the strike of regulating faults, mainly in NE direction, with an opening of 20-50 $\mu \mathrm{m}$, and mainly in grain margin fractures. The reservoir in the study area has the characteristics of dual media, strong reservoir heterogeneity, and the physical properties of the reservoir with the development of micro fractures have been significantly improved, which has an important 
contribution to the reservoir. Micro fractures not only improve the physical properties of reservoir effectively, but also can be used as effective reservoir space.

\section{Conclusion}

The types of Tongbomiao formation in Hongqi sag are feldspathic and lithic sandstone. The pore types include primary intergranular pores, feldspar dissolution pores and debris dissolution pores, and a small amount of intergranular and fractured pores of clay minerals. The porosity is mainly distributed in the range of $6-19.6 \%$, the average is $9.2 \%$, the permeability is mainly distributed in $0.02-43.6 \times 10^{-3} \mu \mathrm{m}^{2}$, with an average of $2.93 \times 10^{-3} \mu \mathrm{m}^{2}$. It is a reservoir of very low porosity and low permeability type.

Although Tongbomiao formation in Hongqi sag is of very low porosity and low permeability type, high quality reservoir is still developed, and its reason is mainly controlled by sedimentary environment, diagenesis and structural fracture. The reservoir of Tongbomiao formation in Hongqi sag mainly develops fan delta system. The physical properties of underwater distributary channel microfacies in fan delta front and above water distributary channel microfacies in fan delta plain are better than those of sheet sand and sublacustrine fan in fan delta front. According to the vertical changes of clay minerals, authigenic minerals and pore types, Tongbomiao formation in Hongqi sag is in the middle diagenetic evolution stage a-b. Hongqi sag has experienced multi-stage tectonic movement. A large number of fault systems developed in the sag. The fault system is not only the channel and reservoir space for oil and gas migration, but also the favorable place and infiltration channel for dissolution. The dissolved matter can be removed with the fluid, which is conducive to the development of secondary pores.

\section{References}

1. Zhang Fangdong, Wang Xuejun, Rao Lei, etc. Main Controlling Factors of Effective Reservoir in the Second Section of Bayingebi of Chagan Sag (Chinese:Journal of Chengdu University of Technology: Science \& Technology Edition) 36 (3): 295-300 (2014)

2. Li Wentao. Sequence stratigraphic characteristics and favorable zone prediction of Nantun Formation in Bayanhushu sag, Hailaer Basin (Chinese:Journal of Yangtze University, Natural Science Edition) 15 (3): 1-9 (2018)

3. Zhang Haiqiao. Evaluation of the hydrocarbon source rock and prediction of the favorable zone in Hongqi Sag of Hailar Basin (Chinese:Petroleum Geology \& Oilfield Development in Daqing) (2): 21-27 (2020)

4. Sun Fajie, Yang Lan. 2016 Geochemistry and tectonic setting of basalts in Tamulangou formation in northern Daxinganling (Chinese:Heilongjiang Science and Technology Information) (2): 13 (2016)
5. Liu Xuewen. 2017 Greater Khingan Range Chaoyuan-Kun NECCHI area middle Jurassic Tamulangou group Geochemical characteristics and genesis (Chinese:World Nonferrous Metals) (7): $97-$ 98 (2017) 